\title{
Thermal Gelation of the Nylon 6,6-Calcium Chloride-Methanol System
}

\author{
Makiko HatToRI and Masatoshi SAITo \\ Fundamental Research Laboratory of Natural \& Synthetic Polymers, Asahi Chemical Industry, \\ 11-7 Hacchonawate, Takatsuki, \\ Osaka 569, Japan
}

(Received August 3, 1995)

\begin{abstract}
An attempt was made to clarify phase transition behavior of nylon 6,6 in a solvent mixture of calcium chloride and methanol on cooling. The nylon 6,6 solution showed turbidity and generated a thermally reversible gel during slow cooling and rapid quenching, followed by aging. Gelation temperature remarkably depended on cooling rate, as well as molecular weight and polymer concentration. The Differential Scanning Calorimetry (DSC) thermogram of the system, that was cooled down at low cooling rate from the dissolution temperature to $25^{\circ} \mathrm{C}$ and followed by aging for various periods, exhibited two endothermic peaks, both of which monotonically grew with increase of aging time up to $100 \mathrm{~h}$. The results of the temperature dependence of X-ray diffraction of the gel aged for 2 days at $25^{\circ} \mathrm{C}$ revealed that crystals generated and grew during gelation. The melting of the crystal was responsible for the endothermic peak at higher temperature side in the DSC thermogram on heating. ${ }^{13} \mathrm{C}$ NMR data on the gel suggested that the solvent molecules, especially calcium chloride associated by methanol molecules, formed an organometal coordination complex with the nylon 6,6 and acted as crosslinking agents in the gel. The gel formed by rapid quenching was regarded as amorphous, because the DSC thermograph showed no apparent endothermic peak on heating. The base line shifted to the endothermic side as usually observed for glass transition of thermoplastic polymers and the gel showed only a hallow pattern in the X-ray diffraction diagram.

KEY WORDS Nylon 6,6 / Calcium Chloride and Methanol Mixture/Phase Diagram / Gelation / Crystallization / Differential Scanning Calorimetry / X-Ray Diffractometry / High Resolution Nuclear Magnetic Resonance/
\end{abstract}

Recently, synthetic polymer gels have attracted much attention, because of industrial utility as ultra-high modulus fibers. A lot of investigations on the underlying mechanism of gelation and structure of the gel have been made for polyolefin, vinyl type polymers, and copolymers. ${ }^{1,2}$ The gelation mechanism of thermoreversible gels has been classified ${ }^{3}$; as crystallization induced gelation, solvent induced (polymer-solvent compound) gelation and glass transition. For example, for poly(ethyleneterephthalate-co-isophthalate) gel, junction points in the gel are composed of crystallites with two types of structures of folded-chain lamellar and fringed micelles. ${ }^{4}$ Regarding the atactic polyvinyl chloride gel, Mutin and Guenet ${ }^{5}$ pointed out that polymer chains with high stereoregularity form crystallites and atactic chains generate polymer-solvent compounds. Guenet et al. ${ }^{6}$ showed that the network of isotactic polystyrene in cis- and transdecalin is constructed of a polymer-solvent compound and in trans-decalin there exists a crystallite of the $3_{1}$ type chain helix. Recently, the existence of this polymersolvent compound type network structure was proved using small angle X-ray diffraction. ${ }^{3,7}$ On the other hand, for atactic polystyrene in decalin system, Arnauts and Berghmans ${ }^{8}$ propose a glass transition of polymer rich phase made by liquid-liquid phase separation as the gelation mechanism.

The previous paper ${ }^{9}$ reported that a mixture of calcium chloride and methanol, in which the weight ratio of calcium chloride against the mixture was termed $W_{\text {ca }}$, is able to dissolve polyhexamethyleneadipamide (nylon 6,6) molecularly near room temperature and the dilute solution of the system showed very characteristic features as follows: The second virial coefficient determined by static light scattering becomes zero at $W_{\text {ca }}=c a .0 .115$, where the nylon 6,6 molecule is in an unperturbed state and behaves as a very flexible chain: Methanol molecules form a coordination complex with undissociated $\mathrm{CaCl}_{2}$ in the range of $W_{\mathrm{ca}} \geq 0.10$ : These organometallic complexes play important roles in the dissolution of the polymer and stabilization of the solution. From these results we can expect that if the interaction between nylon 6,6 chains and the organometallic complex is even partially destroyed at appropriate temperature, phase transition or physical gelation in some cases occurs due to reconstruction of hydrogen bonds between nylon 6,6 chains (i.e., crystallization or glass transition induced gel), or participation of solvent molecules as crosslinking reagents (solvent induced gel).

In this paper, our phenomenological approach to disclose gelation phenomena of the nylon 6,6 solution on cooling is reported and the network structure of the gel obtained by two different cooling rates is discussed on the basis of DSC, X-ray diffraction and high resolution solid (CP/MAS) and solution modes ${ }^{13} \mathrm{C}$ NMR data.

\section{EXPERIMENTAL}

\section{Samples}

Nylon 6,6 (Asahi Chemical Industry Co., Tokyo), polymerized by polycondensation from hexamethylenediamine and adipic acid, was used as the starting sample (code PC1). The numbers of end groups of $\mathrm{COOH}$ and $\mathrm{NH}_{2}$ groups were 55.0 and $58.9 \mathrm{mg}$ equivalent per $\mathrm{kg}$ and the weight-average $\left(M_{w}\right)$ and the viscosity-average molecular weight $\left(M_{v}\right)$ were $4.4 \times 10^{4}$ and $3.6 \times 10^{4}$, respectively. ${ }^{9}$ Two samples, code SP1 and SP10, were prepared from the sample PCl by solid phase polymerization under the following conditions: temperature, $220 \pm 10^{\circ} \mathrm{C}$; rate of flowing nitrogen gas, 0.4 liter per minute; time, $1 \mathrm{~h}$ for SP1 and $10 \mathrm{~h}$ for SP10. The limiting 
viscosity number $[\eta]$ of the samples obtained were determined by Huggins plots using $98 \%$ aqueous sulfuric acid solution as solvent at $25^{\circ} \mathrm{C}$. $M_{v}$ was estimated by the following Mark-Houwink-Sakurada equation ${ }^{10}$ to be $1.55 \times 10^{5}$ and $4.0 \times 10^{5}$ for the samples SP1 and SP10, respectively.

$$
[\eta]=6.3 \times 10^{-2} M_{w}^{0.73}\left(\mathrm{~cm}^{3} \mathrm{~g}^{-1}, 25^{\circ} \mathrm{C}\right)
$$

\section{Solution Preparation}

A mixture of methanol and calcium chloride with weight concentration of $\mathrm{CaCl}_{2}\left(W_{\mathrm{ca}}\right)=0.23$ (wt/wt) was prepared. Each sample was swollen in the mixture for at least one day at room temperature, followed by dissolution at $80^{\circ} \mathrm{C}$. The polymer solutions with polymer concentration $C_{\mathrm{p}}$ ranging from 0.005 to 0.15 (wt/wt) and $W_{\text {ca }}$ of $0.125,0.15,0.175$, and 0.20 were prepared by dilution with methanol.

\section{Phase Diagram}

$10 \mathrm{ml}$ of the polymer solution were put into a cylindrical ampule of $20 \mathrm{ml}$. In order to avoid possible degradation of the polymer, air in the ampule was replaced by nitrogen gas before hermetical sealing. The ampule was set in the bath thermostatted at $\pm 0.1^{\circ} \mathrm{C}$. Then the solution was cooled 5 degree a day at a rate of $1.75^{\circ} \mathrm{Ch}^{-1}$ from the starting temperature $T_{\mathrm{s}}(=75$ or $78^{\circ} \mathrm{C}$ ) to a desired temperature $T$ and the system was held at each temperature for one day (referred to slow cooling method). $1 \mathrm{ml}$ of the polymer solution was put into a cylindrical ampule of $2 \mathrm{ml}$. The system was quenched by transferring the ampule from the bath controlled at $T_{\mathrm{s}}=75^{\circ} \mathrm{C}$ to another at temperature $T_{\mathrm{q}}$ lower than $0^{\circ} \mathrm{C}$ (rapid quenching method).

For observation of the turbidity point, a $\mathrm{He}-\mathrm{Ne}$ laser beam with wave length of $633 \mathrm{~nm}$ was irradiated on the system. The temperature at which scattered light in the vertical direction to the incident beam was detected was the turbidity point of the system. Determination of gel state was made by the inversion method: The system which showed no detectable fluidity in $10 \mathrm{~min}$ after inversion was defined as gel in this study.

\section{Differential Scanning Calorimetry}

The two types of gels for DSC measurements were prepared in an ampule by the following two methods: Cooling the solution from $75^{\circ} \mathrm{C}$ to $25^{\circ} \mathrm{C}$ at a rate of about $1^{\circ} \mathrm{C} \mathrm{min}^{-1}$, followed by aging for time $t_{\mathrm{a}}=5 \mathrm{~h}-2$ months (hereafter this method is referred to as the slow cooling method); rapidly quenching the solution from $T_{\mathrm{s}}=75^{\circ} \mathrm{C}$ to $T_{\mathrm{q}}=-70^{\circ} \mathrm{C}$, followed by aging for $30 \mathrm{~min}$ (rapid quenching method). DSC measurements were carried out after loading the gel in a seal cell using DSC type 200 (Seiko Electronic Co., Tokyo). The heating rate was $2^{\circ} \mathrm{C} \mathrm{min}{ }^{-1}$, unless otherwise stated, for slow cooling gel and $5^{\circ} \mathrm{C} \mathrm{min}{ }^{-1}$ for rapid quenching one.

\section{High Resolution $-{ }^{13} \mathrm{C} N \mathrm{NR}$}

Solid and solution mode ${ }^{13} \mathrm{C}$ NMR measurements were performed on the sample PC1 gels with $C_{\mathrm{p}}=0.10$ and $W_{\text {ca }}=0.15$ at $25^{\circ} \mathrm{C}$, prepared by slow cooling from $75^{\circ} \mathrm{C}$ to $25^{\circ} \mathrm{C}$ at a rate of $1{ }^{\circ} \mathrm{C} \mathrm{min}^{-1}$, followed by aging at the same temperature in a capillary for NMR measurements.
Chemical shifts were measured relative to external adamantane (upfield peak, $\delta=29.5 \mathrm{ppm}$ ) for the solid mode and to internal tetramethylsilane (TMS, $\delta=0 \mathrm{ppm}$ ) for the solution mode NMR studies. NMR spectra were recorded on NMR-FX200 (JOEL, Tokyo). In the case of solid mode measurements, enhancement of signals from the system was achieved with cross polarization and magic angle spinning (CP/MAS) under the following conditions: Angle, $90^{\circ}$; width, $5 \mu \mathrm{s}$; repetition, $5 \mathrm{~s}$; cross-polarization contact time, $1-2 \mathrm{~ms}$; data points, 8192; number of scanning, 1440 times. Conditions of the solution mode NMR were: Angle, $45^{\circ}$; pulse width, $6.5 \mu \mathrm{s}$; repetition, $3.6 \mathrm{~s}$; number of scanning, 1440 times.

\section{Wide Angel X-Ray Diffractometry}

For the PCl gel sample $\left(C_{\mathrm{p}}\right.$ and $W_{\text {ca }}, 0.15$ and 0.15$)$ formed by the slow cooling at $T=25^{\circ} \mathrm{C}$ followed by aging for $48 \mathrm{~h}$, change of diffraction on heating from 25 to $54^{\circ} \mathrm{C}$ was measured using heating treatment equipment model CN2311B1 (Rigaku, Tokyo). Measurement on the same sample gel prepared by rapid quenching at $-70^{\circ} \mathrm{C}$ and aged for $1 \mathrm{~h}$ was made at that temperature with a cryo refrigerator model S030 (Iwamoto Cryo Techno Co., Tokyo). Diffraction was recorded on X-ray diffractometer type RU-300 (Rigaku, Tokyo) using $K_{\alpha}$ rays of copper as the incident beam.

\section{RESULTS AND DISCUSSION}

\section{Phase Diagrams}

Figures 1-a,b,c show the phase diagrams obtained by slow cooling method for the sample SP1 system with $W_{\text {ca }}=0.125$ (a), 0.15 (b), and 0.175 (c). The turbidity point (solid line) was observed irrespective of $W_{\text {ca }}$ and polymer concentration. Obviously, the solution region is wider for the system with higher $W_{\text {ca }}$, due to the fact that the mixture of calcium chloride and methanol becomes a good solvent for nylon 6,6, with an increase of $W_{\mathrm{ca}} \cdot{ }^{9}$ At fixed polymer concentration, every system, except for $W_{\mathrm{ca}}=0.125$ and $C_{\mathrm{p}}$ lower than 0.02 (smeared area in Figure 1a), undergoes gelation (shadowed area) below turbidity point. At $W_{\mathrm{ca}}=0.125$ and $C_{\mathrm{p}}$ lower than 0.02 , there is no gel, but a white precipitate below $20^{\circ} \mathrm{C}$. Every nylon 6,6 gel obtained by slow cooling readily turns to solution by elevation of temperature (i.e., thermoreversible gel).

Figures 2 and 3 show gelation time $t^{\mathrm{G}}$, defined as the time required for gelation to occur after rapid quench-

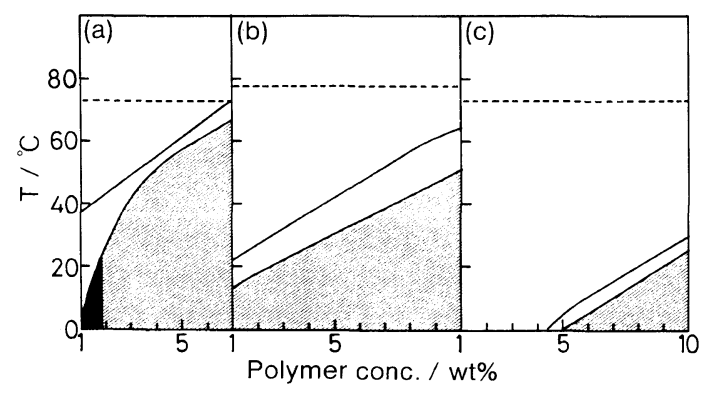

Figure 1. Phase diagram of nylon $6,6\left(M_{v}=1.55 \times 10^{5}\right) \mathrm{CaCl}_{2}-$ methanol system with $W_{\text {ca }}=0.125(\mathrm{a}), 0.150$ (b), and 0.175 (c), when the system was cooled at a rate of $1.75^{\circ} \mathrm{Ch}^{-1}$. Broken line, dissolution temperature $T_{\mathrm{s}}$ of the polymer; solid line, turbidity point curve; shadowed area, gel phase; smeared out area, precipitation phase. 
ing, plotted against $T_{\mathrm{q}}$ for the samples PC1 and SP1, respectively. Number on the curve indicates polymer concentration. Inspection of these figures reveals that $t^{\mathrm{G}}$ generally becomes smaller with increase in polymer concentration and molecular weight and decrease in $W_{\text {ca. }}$. Similar to other thermally induced gels of natural ${ }^{11}$ and synthetic polymers, ${ }^{1,2}$ the thermal history of the sample, such as cooling rate and aging time, is an important factor to determine phase of the nylon 6,6-calcium-methanol system. In Figures 4 and 5 the phase diagrams of the sample PCl and SP1 systems in $30 \mathrm{~min}$ after quenching are drawn. Like the case of slow cooling, gelation occurs below the turbidity point except for the

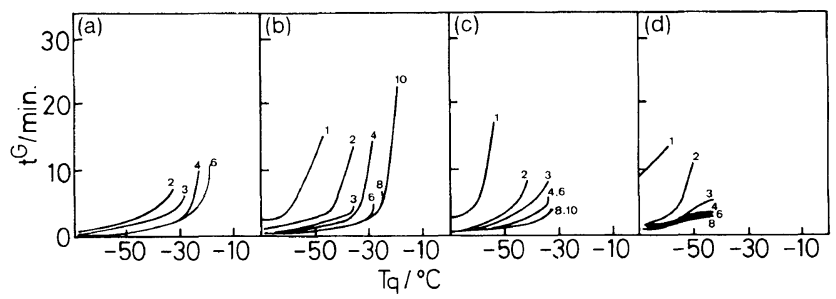

Figure 2. Relationship between gelation time $t^{\mathrm{G}}$ and temperature $T_{q}$ at which the nylon $6,6\left(M_{\mathrm{v}}=3.6 \times 10^{4}\right)-\mathrm{CaCl}_{2}-$ methanol system was quenched; $W_{\mathrm{ca}}=0.125$ (a), 0.150 (b), 0.175 (c), 0.200 (d). Number on the line denotes polymer concentration $C_{\mathrm{p}}$.

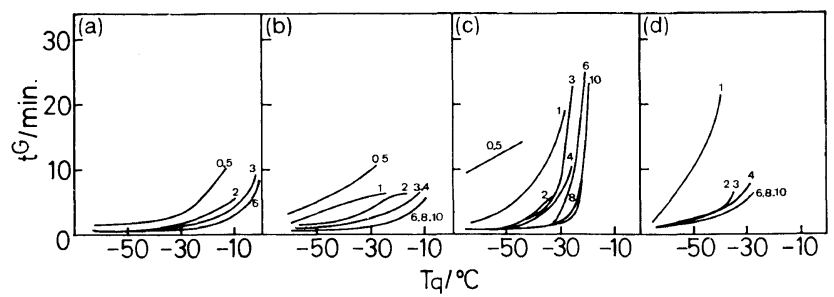

Figure 3. Relationship between gelation time $t^{\mathrm{G}}$ and temperature $T_{\mathrm{q}}$ at which the nylon $6,6\left(M_{\mathrm{v}}=1.55 \times 10^{5}\right)-\mathrm{CaCl}_{2}-$ methanol system was quenched; $W_{\text {ca }}=0.125$ (a), 0.150 (b), 0.175 (c), 0.200 (d). Number on the line denotes polymer concentration $C_{\mathrm{p}}$.

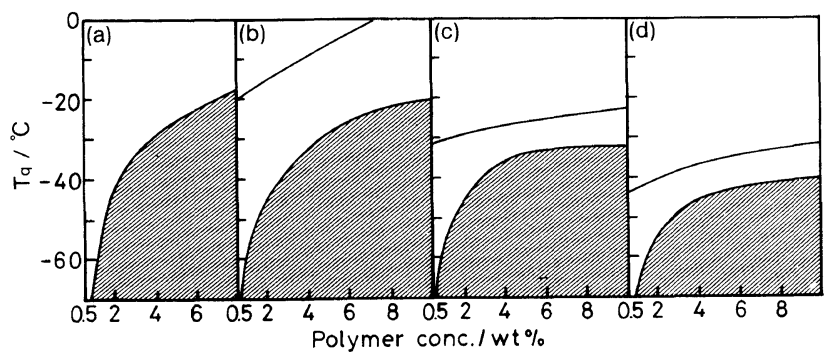

Figure 4. Phase diagram of nylon $6,6\left(M_{\mathrm{v}}=3.6 \times 10^{4}\right)-\mathrm{CaCl}_{2}-$ methanol system with $W_{\text {ca }}=0.125$ (a), 0.150 (b), 0.175 (c), and 0.200 (d), when the system was quenched. Solid line, cloud point curve; shadowed area, gel phase.

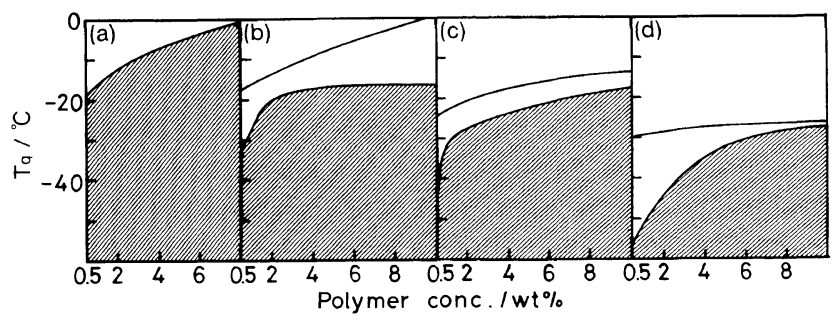

Figure 5. Phase diagram of nylon 6,6 $\left(M_{\mathrm{v}}=1.55 \times 10^{5}\right)-\mathrm{CaCl}_{2}-$ methanol system with $W_{\text {ca }}=0.125$ (a), 0.150 (b), 0.175 (c), and 0.200 (d), when the system was quenched. Solid line, cloud point curve; shadowed area, gel phase. samples $\mathrm{PC} 1$ and $\mathrm{SP} 1$ with $W_{\mathrm{ca}}=0.125$. PC1 and SP1 with $W_{\text {ca }}=0.125$ are expected to have turbidity points above $0^{\circ} \mathrm{C}$, because both were clouded below that temperature. The gel obtained by this method readily melts by heating near $0^{\circ} \mathrm{C}$, at which the system cooled slowly still remains in gel state as shown in Figure 1, suggesting that the interaction between polymeric chains at junction points in the gel formed by rapid quenching is weaker than that in the gel obtained by slow cooling.

\section{Structure of The Gel Formed by Slow Cooling}

Figure 6 represents the DSC thermograms of the sample $\mathrm{PC} 1$ system cooled down at a rate of about $1^{\circ} \mathrm{C} \mathrm{min}^{-1}$ to $25^{\circ} \mathrm{C}$, followed by aging for time $t_{\mathrm{a}}$. Here, it should be noted that this system was turbid and fluid, showing no endotherm up to $t_{\mathrm{a}}=3 \mathrm{~h}$. Interestingly, the system of $t_{\mathrm{a}}=5 \mathrm{~h}$ loses its fluidity and its DSC curve shows a very broad endothermic peak at $50^{\circ} \mathrm{C}$ (peak I) and shoulder (peak II) near $40^{\circ} \mathrm{C}$. The latter becomes remarkable with increase in $t_{\mathrm{a}}$. The peak temperature of peaks I and II and end point of peak I are almost independent of $t_{\mathrm{a}}$, while an onset point of peak II slightly increases with $t_{\mathrm{a}}$.

Guenet et $a{ }^{6}{ }^{6}$ reported that the gel of iso-tactic polystyrene/cis-decalin system exhibits two endothermic peaks in the DSC thermogram on heating and claim a part of the total heat of fusion $\Delta H_{\mathrm{T}}$ of the two peaks is brought out by kinetic effect due to contact of the gel to the DSC sample cell, because $\Delta H_{\mathrm{T}}$ is larger for the system with lower viscosity, in other words, for the sample with low molecular weight, and remarkably depends on the heating rate.

In Figure 7, DSC curves of the nylon 6,6 gel with three molecular weights, aged for $t_{\mathrm{a}}=24 \mathrm{~h}$ at $25^{\circ} \mathrm{C}$, are illustrated. Here $C_{\mathrm{p}}$ and $W_{\mathrm{ca}}$ of the gel are fixed at 0.10 and 0.15 , respectively. Obviously, an increase in molecular weight brings about increase in melting

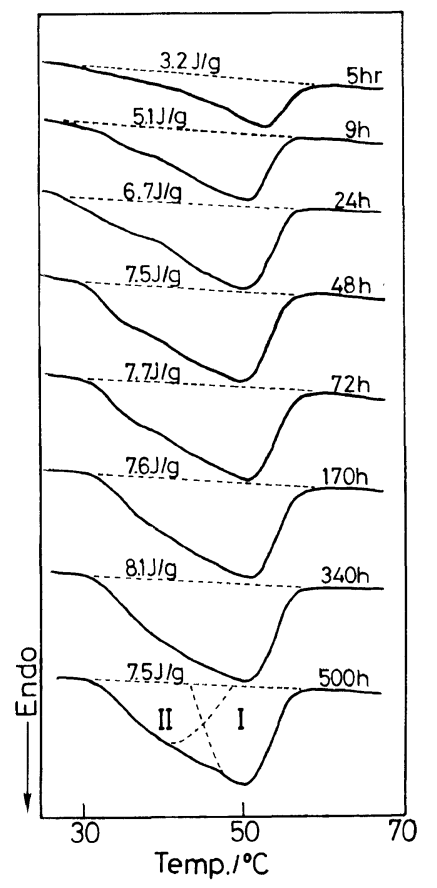

Figure 6. DSC curves of gels of nylon $6,6\left(M_{\mathrm{v}}=3.6 \times 10^{4}\right)$, aged at $25^{\circ} \mathrm{C}$ for various periods $t_{\mathrm{a}}$. Broken line denotes base line. Numbers on each curve mean $t_{\mathrm{a}}$ and heat of fusion. 


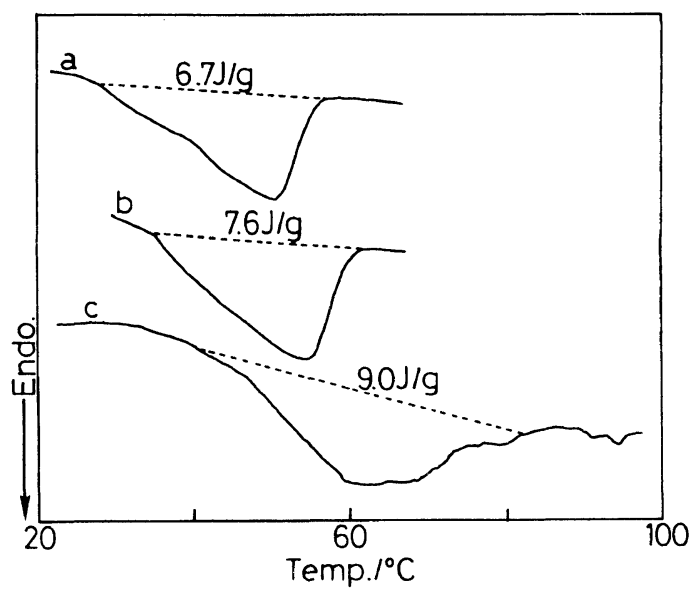

Figure 7. DSC curves of gels of nylon $6,6 M_{\mathrm{v}}=3.6 \times 10^{4}(\mathrm{a}), 1.55 \times 10^{5}$ (b), and $M_{\mathrm{v}}=4.0 \times 10^{5}(\mathrm{c}), C_{\mathrm{p}}=0.1$ and $W_{\mathrm{ca}}=0.15$, aged at $25^{\circ} \mathrm{C}$ for $24 \mathrm{~h}$. Numbers on the curves denote total heat of fusion.

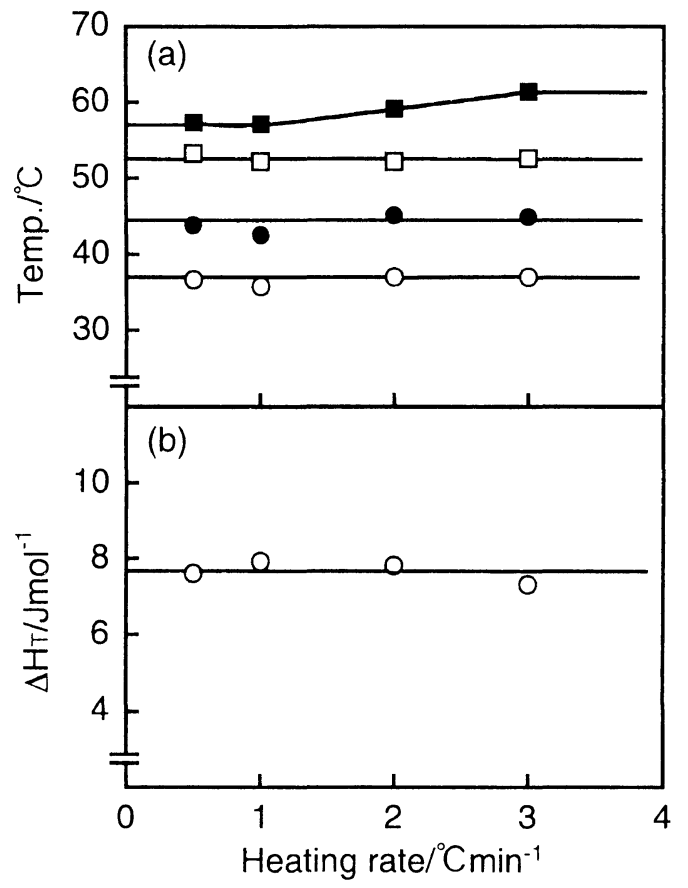

Figure 8. Heating rate dependence of onset $(\bigcirc)$, peak II $(\bigcirc)$, peak I ( $\square$ ), end point ( $\square$ ) (a) and total heat of fusion $\Delta H_{\mathrm{T}}$ (b) for gels with $C_{\mathrm{p}}=0.1$ and $W_{\mathrm{ca}}=0.15$, aged at $25^{\circ} \mathrm{C}$ for two months.

enthalpy besides onset and end points of melting. In addition, the peak temperatures and $\Delta H_{\mathrm{T}}$ are almost independent of the heating rate for the gel (PC1, $C_{\mathrm{p}}=0.10, W_{\text {ca }}=0.15$ and $t_{\mathrm{a}}=2$ months), as shown in Figures $8 \mathrm{a}$ and $8 \mathrm{~b}$. These facts perfectly deny the possibility of the kinetic effect on $\Delta H_{\mathrm{T}}$ for this system.

Several mechanisms for the appearance of two endothermic peaks in the DSC thermogram of the gel are introduced in the review of Guenet ${ }^{3}$ : For the gel of polyethylene in decalin, Smith and Lemstra ${ }^{12}$ conclude that recrystallization after the melt of crystallites with low crystallinity takes place in the system, because a decrease of the heating rate brings about increase of the heat of fusion of the higher position peak and peak position shifts to the higher temperature side, whereas the heat of fusion of lower position peak decreases. The gel of syndiotactic poly(methyl methacrylate)(PM$\mathrm{MA}) / o$-xylene system is also reported to show the

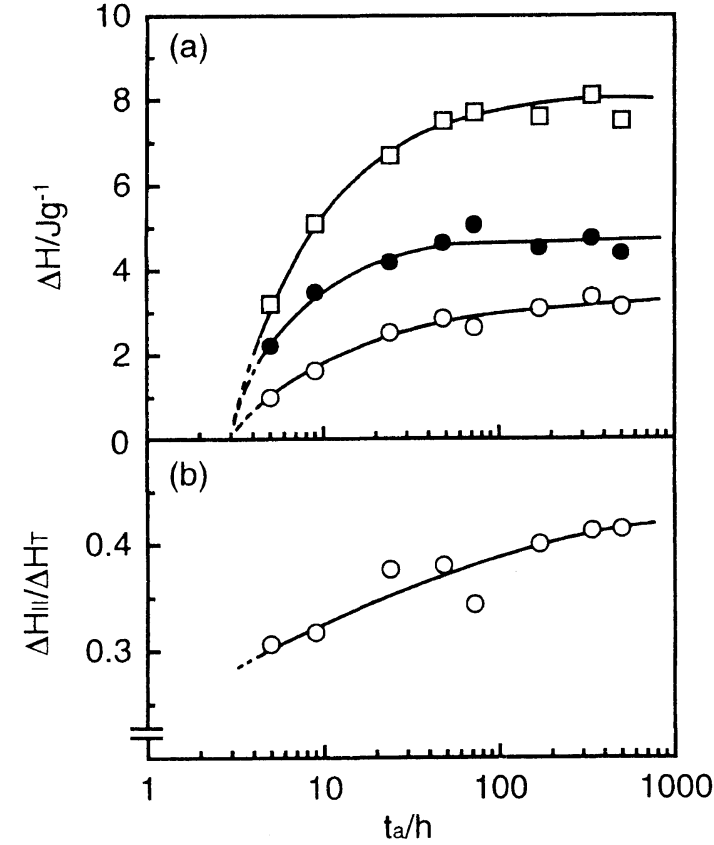

Figure 9. Heat of fusion (a) of peak I ( $\Delta H_{\mathrm{I}}$, filled circle), peak II $\left(\Delta H_{\mathrm{II}}\right.$, unfilled circle) and total $\left(\Delta H_{\mathrm{T}}\right.$, rectangle) and ratio of $\Delta H_{\mathrm{II}}$ to $\Delta H_{\mathrm{T}}(\mathrm{b})$ for the gels of nylon $6,6\left(M_{\mathrm{v}}=3.6 \times 10^{4}\right)$ plotted against the logarithm of aging time $t_{\mathrm{a}}$.

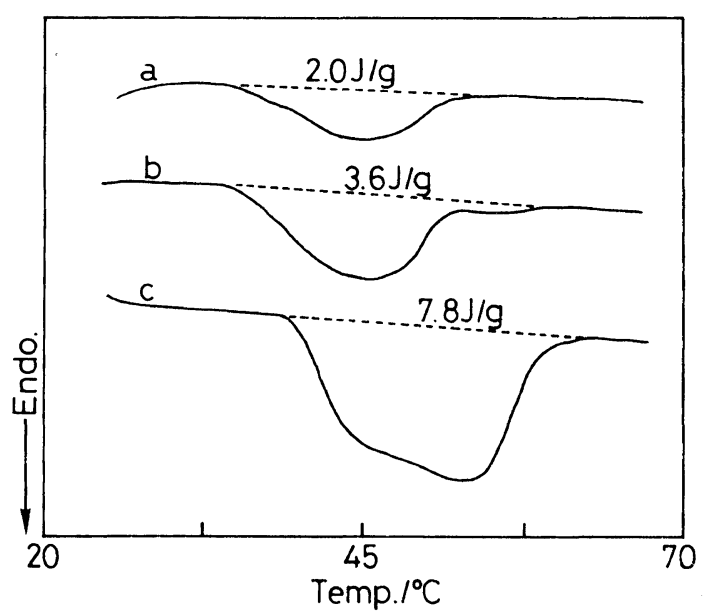

Figure 10. DSC curves of nylon $6,6\left(M_{\mathrm{v}}=3.6 \times 10^{4}\right)$ gel with $W_{\mathrm{ca}}=$ 0.15 , aged at $25^{\circ} \mathrm{C}$ for two months. $C_{\mathrm{p}}=0.03$ (a), 0.05 (b), and 0.10 (c).

appearance and growth of another peak at lower temperature side by annealing and elevation of polymer concentration for an unannealed gel. Könnecke and Rehage $^{13}$ assigned the double peaks after annealing to melting of the crystallites formed during gelation on cooling for the higher temperature peak and during the annealing for the lower temperature peak. This is because the heat of fusion of higher temperature peak is almost independent of annealing time. In the case of the unannealed gel with higher polymer concentration, they supposed that the less mobility of the molecules in condensed solution leads to generation of small crystallites which melt at lower temperature and recrystallize to bigger ones during DSC scanning and their melting is responsible for the second peak at higher temperature. The annealing time dependence of the heat of fusion of peak I $\left(\Delta H_{1}\right)$ and II $\left(\Delta H_{\mathrm{II}}\right), \Delta H_{\mathrm{T}}$ and ratio $\Delta H_{\mathrm{II}} / \Delta H_{\mathrm{T}}$ estimated from the areas of DSC endothermic curve in Figure 6 are shown in Figures 9a and b. Contrary 
to the annealed PMMA gel, peaks I and II of nylon 6,6 gel are generated almost at the same aging time and grow concomitantly during aging, while the rate of growth of $\Delta H_{\mathrm{II}}$ is slightly larger than that of $\Delta H_{\mathrm{I}}$.

In Figure 10, the effect of polymer concentration on the melting of the nylon 6,6 gel with $W_{\text {ca }}=0.15$ and $t_{\mathrm{a}}=2$ months when the gel is in equilibrium is illustrated. The gel with low polymer concentration $\left(C_{\mathrm{p}}=0.03\right)$, i.e., high mobility, shows only one peak (peak II) and peak position is independent of $C_{\mathrm{p}}$. When $C_{\mathrm{p}}$ is 0.05 , another endothermic peak appears near $53^{\circ} \mathrm{C}$, which becomes very apparent at $C_{\mathrm{p}}=0.10$. This disproves that peak II is ascribed to the melt of crystallites generated due to less mobility of molecules in condensed solution.

Figure 11 shows change of $\mathrm{X}$-ray diffraction diagram of the gel formed and aged at $25^{\circ} \mathrm{C}$ for $48 \mathrm{~h}$. In the figure, the diffraction of the solid of the sample PC1, the nylon $6,6 \alpha$ triclinic crystal system, ${ }^{14}$ is depicted for comparison. The diagram of the gel at $33^{\circ} \mathrm{C}$ which is very close to the onset point of peak II in the DSC thermogram of the gel of $t_{\mathrm{a}}=48$ (see, Figure 6) clearly shows two peaks at scattering angles $2 \theta=20.8$ and $24.4^{\circ}$, very near to those of $\alpha$ triclinic crystal. The peak at $2 \theta=20.8^{\circ}$ starts to decrease in intensity at $48^{\circ} \mathrm{C}$ which is approximately equal to the onset point of peak $\mathrm{I}$ in the DSC thermogram and remains at $54^{\circ} \mathrm{C}$ which is about $5^{\circ} \mathrm{C}$ higher than the end point of peak II. It is worth noting that a slight increase in diffraction intensity due to recrystallization is observed in the temperature range measured.

These facts indicate at least that in the gel formed by slow cooling, there exist crystals generated not from

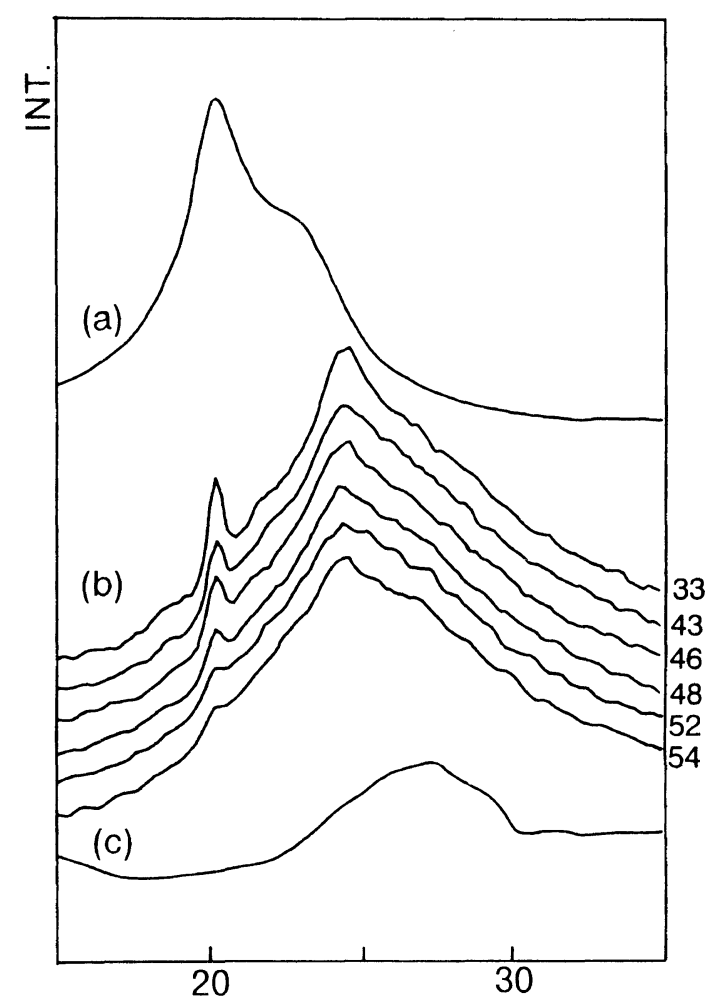

$2 \theta /$ degree

Figure 11. X-Ray diffractograms of nylon 6,6 solid (a) and gel of the sample PC1 prepared by slow cooling (b) and rapid quenching (c). Numbers on the lines of gel prepared by slow cooling method denote the temperature of measurement. recrystallization during DSC scan, but during gelation and peak $I$ in the DSC thermogram is responsible for the melt of the crystals. But evidence that peak II originates from the melt of crystal or crystallites was not obtained from the temperature dependence of X-ray diffraction.

Figure 12 shows solid mode $\mathrm{CP} / \mathrm{MAS}{ }^{13} \mathrm{C}$ NMR spectra of the system of $t_{\mathrm{a}}=0-70 \mathrm{~h}(\mathrm{a}-\mathrm{f})$ and the solution mode NMR spectrum of the gel of $t_{\mathrm{a}}=70 \mathrm{~h}\left(\mathrm{f}^{\prime}\right)$ for the sample $\mathrm{PC} 1$ at $25^{\circ} \mathrm{C}$. Interestingly, no peak was detected by solid mode NMR when the system showed apparent fluidity $\left(t_{\mathrm{a}}=0-3 \mathrm{~h}\right)$. But several peaks from the carbons of methanol molecules (methyl carbon, near $50 \mathrm{ppm})^{9}$ as well as those of polymer (methylene and carbonyl carbons, 25-45 and near $175 \mathrm{ppm})^{15,16}$ were detected when the system lost its fluidity (above $t_{\mathrm{a}}=5$ ), just corresponding to the appearance of the endothermic peaks in DSC thermogram of the system. The peak intensity of the methanol, compared to those of methylene carbons of polymer, monotonically increases with $t_{\mathrm{a}}$, i.e., with the growth of the gel, indicating that methanol molecules participate in the formation of a network in the gel. The results of the solution mode NMR, IR, and adiabatic compressibility measurements on the nylon 6,6 solution with $C_{\mathrm{p}}=0.01-0.02$ and $W_{\text {ca }}$ ranging from 0.125 to $0.20,{ }^{9}$ revealed that the nylon 6,6 polymers dissolve in the calcium-chloride and methanol mixture forming the organometallic coordination complex, such as $\mathrm{R}-\mathrm{C}^{\delta+}=\mathrm{O}^{\delta-} \Leftrightarrow \mathrm{Ca}^{2+} \cdot\left(\mathrm{CH}_{3} \mathrm{OH}\right)_{n} \cdot 2 \mathrm{Cl}^{-}$and $\mathrm{R}^{\prime}-\mathrm{N}^{\delta+} \mathrm{H} \Leftrightarrow \mathrm{Cl}^{-} \cdot\left(\mathrm{CH}_{3} \mathrm{OH}\right)_{n / 2} \cdot 1 / 2 \mathrm{Ca}^{2+}$ (here, association

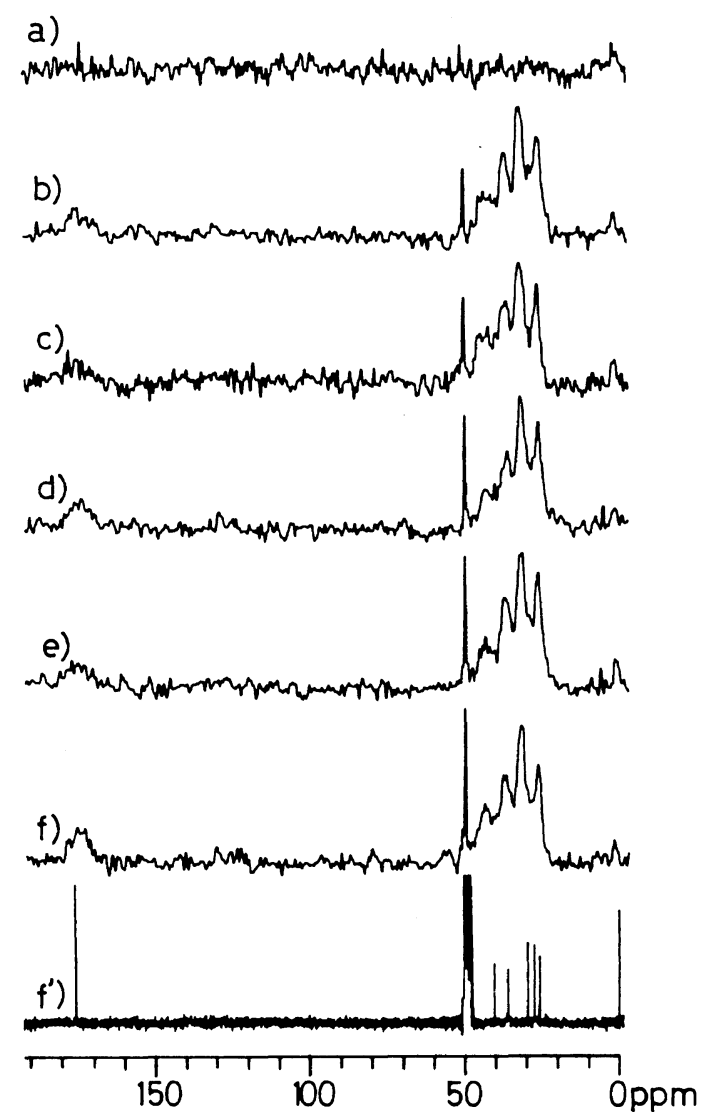

Figure 12. Solid mode $(a-f)$ and solution $\left(f^{\prime}\right)$ mode ${ }^{13} \mathrm{C}$ NMR spectra of the gel of the sample PC1 prepared by slow cooling at $25^{\circ} \mathrm{C}$. The gel was aged at $25^{\circ} \mathrm{C}$ for $0 \mathrm{~h}$ (a) (the system remains solution state);

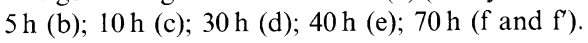


Table I. NMR chemical shifts of carbon atoms of nylon 6,6 molecules and methyl carbon of methanol in gel and solution detected by solution mode NMR measurement

\begin{tabular}{|c|c|c|c|c|c|c|c|c|}
\hline \multirow{2}{*}{$\begin{array}{c}\text { State of } \\
\text { N6,6 }\end{array}$} & \multirow{2}{*}{$\operatorname{Temp} /{ }^{\circ} \mathrm{C}$} & \multicolumn{7}{|c|}{ Chemical shift/ppm } \\
\hline & & $\mathrm{C}=\mathrm{O}$ & $\alpha-\mathrm{C}=\mathrm{O}$ & $\beta-\mathrm{C}=\mathrm{O}$ & $\alpha-\mathrm{NH}$ & $\beta$-NH & $\gamma-\mathrm{NH}$ & $\mathrm{CH}_{3} \mathrm{OH}$ \\
\hline Gel & 25 & 175.9 & 36.0 & 25.9 & 40.5 & 29.8 & 27.4 & 49.1 \\
\hline Solution $^{a}$ & 40 & 176.1 & 36.1 & 25.9 & 40.6 & 29.8 & 27.5 & 49.2 \\
\hline
\end{tabular}

${ }^{\text {a }}$ Reference 9

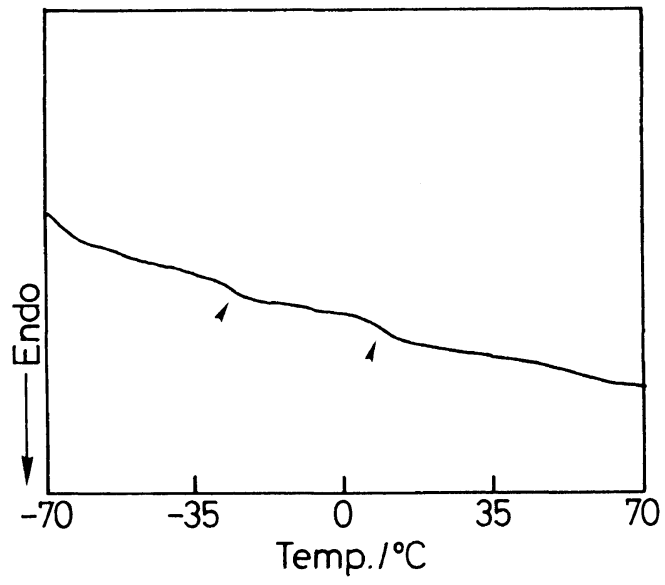

Figure 13. DSC thermogram of sample PCl gel formed by quenching method at $-70^{\circ} \mathrm{C}$, and aged for $30 \mathrm{~min}$.

number $n$ ranges from 4 to 8 , depending on $W_{\text {ca }}$ ). The appearance and growth of the NMR peak of the methanol during gelation may be plausibly explained considering that calcium chloride associated with methanol molecules weakly interacts with the nylon 6,6 polymers by lowering of temperature and such a polymer-solvent coordination complex junctions as a crosslinking reagent in the network. This kind of crosslinks is readily broken at lower temperature than the melting point of crystals in the gel by heating, which is considered the reason for peak II in the DSC thermogram.

The difference of the solution mode NMR chemical shift of the solution and gel is very small (within $0.2 \mathrm{ppm}$ ), as shown in Table I. At this stage, it is not clear whether the turbidity of the solution due to cooling is related to liquid-liquid phase separation or not, but even in the gel some nylon 6,6 molecules surely dissolve in quite the same manner as in solution.

\section{Structure of The Gel Formed by Rapid Quenching}

Figure 13 shows the DSC thermogram of the sample PC1 gel generated by rapid quenching at $-70^{\circ} \mathrm{C}$. The gel shows no endothermic peak, but a base line shift to the endothermic side near $-30^{\circ} \mathrm{C}$ and $0^{\circ} \mathrm{C}$, corresponding to the glass transition. In addition, as shown in Figure 11(c), we could not detect any trace of crystallites in this gel aged for $1 \mathrm{~h}$ at $-70^{\circ} \mathrm{C}$ by $\mathrm{X}$-ray diffraction. These facts lead us to the conclusion that rapid quenching of the nylon 6,6 solution below $0^{\circ} \mathrm{C}$ only induces the amorphous gel in which only very frail hydrogen bonds are formed between polymer chains and this gel has a far lower melting point than that of the gel generated by slow cooling.

\section{CONCLUSIONS}

1. The nylon 6,6-calcium chloride-methanol system generates a thermally reversible gel below the turbidity point by slow and rapid cooling followed by aging.

2. Gelation temperature differs from cooling rate and at the same cooling rate it remarkably depends on solvent composition, polymer concentration and molecular weight.

3. Gelation by slow cooling is closely related to the crystallization of polymer chains and possibly to the formation of the organometal coordination complex between polymeric chains and solvent molecules.

4. In the case of rapid quenching, the gel obtained is amorphous and turns to solution at far lower temperature than the gel obtained by slow cooling.

Acknowledgments. The authors express their sincere gratitude to Prof. K. Kamide at Kumamoto University, Dr. K. Okajima at the author's laboratory for invaluable comments and $\mathrm{Mr}$. Y. Itoh for assistance in making $\mathrm{X}$-ray diffraction measurements on the gels.

\section{REFERENCES}

1. See for example, P. S. Russo, Ed., "Reversible Polymeric Gels and Related Systems," ACS Symposium Series 350, American Chemical Society, Washington, D.C., 1987.

2. W. Burchard and S. B. Ross-Murphy, "Physical Networks," Elsevier Applied Science, New York, N.Y., 1990.

3. J. Guenet, "Thermoreversible Gelation of Polymers and Biopolymers," Academic Press Inc., London, 1992, Chapter 1.

4. H. Berghmans, F. Govaerts, and N. Oberbergh, J. Polym. Sci., Polym. Phys. Ed., 17, 1251 (1979).

5. P. H. Mutin and J. M. Guenet, Macromolecules, 22, 843 (1989).

6. J. M. Guenet and G. B. McKenna, Macromolecules, 21, 1752 (1988).

7. M. Klein, A. Brulet, and J. M. Guenet, Macromolecules, 23, 540 (1990). M. Klein, J. M. Guenet, A. Brulet, and F. Boue, Polymer, 32, 1943 (1991)

8. J. Arnauts and H. Berghmans, Polym. Commun., 28, 66 (1987).

9. M. Hattori, M. Saito, K. Okajima, and K. Kamide, Polym. J., 27, 631 (1995).

10. K. Kamide, A. Kataoka, and K. Kawai, Makromol. Chem., 139, 221 (1970).

11. K. Kamide, M. Saito, and K. Yasuda, ACS Symposium Series 489, American Chemical Society, Washington, D.C., 1992, Chapter 12.

12. P. Smith and P. J. Lemstra, J. Mater. Sci., 15, 505 (1980).

13. K. Könnecke and G. Rehage, Makromol. Chem., 184, 2679 (1983).

14. C. W. Bunn and E. V. Garner, Proc. R. Soc. (London), Ser. A, 189, 39 (1947).

15. K. Kubo, I. Ando, T. Shiibashi, and T. Komoto, J. Polym. Sci., Part B: Polym. Phys., 29, 57 (1991).

16. B. S. Holmes, W. B. Moniz, and R. C. Ferguson, Macromolecules, 15, 129 (1982). 